\title{
Effect of curing degree on mechanical and thermal properties of 2.5D quartz fiber reinforced boron phenolic composites
}

https://doi.org/10.1515/epoly-2019-0048

Received February 23, 2019; accepted May 30, 2019.

Abstract: 2.5D quartz fiber reinforced boron phenolic composites with different curing degrees were prepared by different curing temperatures and curing times. The effects of curing degree on the flexural strength and thermal properties of the composites were investigated by mechanical properties test, scanning electron microscope (SEM) and thermogravimetric analysis (TGA). The results show that the flexural strength increases to the increase in the degree of cure, but the rate of increase is non-linear. When the degree of cure is higher than $90 \%$, the flexural strength of the composite is more than $300 \mathrm{MPa}$ and the bending failure mechanism of the composite is analyzed by SEM. The TG test showed that the degree of cure had little effect on the residual weight of the composite at $1000^{\circ} \mathrm{C}$, but had a greater effect on the temperature of the previous weight loss.

Keywords: 2.5D quartz fiber; boron phenolic; degree of cure; failure mechanism; residual weight

\section{Introduction}

Multidimensional woven fiber reinforced composites has many advantages over traditional two-dimensional (2D) fiber reinforced composites, such as excellent inter laminar shear resistance and excellent integrity. However, three-dimensional (3D) woven fibers have the

\footnotetext{
* Corresponding author: Yan Qin, Key Laboratory of Special Functional Materials Technology of Ministry of Education, Wuhan University of Technology, Wuhan, 430070, China, e-mail: qinrock@sina.com Huadong Fu, Xin He, Xinyue Meng, Yiyou Zhong and Zhenyue Zou, Key Laboratory of Special Functional Materials Technology of Ministry of Education, Wuhan University of Technology, Wuhan, 430070, China
}

disadvantages of complicated production process and high production cost. The appearance of $2.5 \mathrm{D}$ woven technology has greatly improved the shortcomings of 3D woven, while retaining the advantages of multidimensional woven fibers (1-4). Quartz fiber has good high temperature resistance, long-term use temperature up to $1200^{\circ} \mathrm{C}$, and has good mechanical properties and permeability (5). Boron phenolic resin is a resin matrix commonly used for high temperature and ablation resistant composites (6,7). Therefore, the 2.5D quartz fiber reinforced boron phenolic resin matrix composite has excellent mechanical properties, especially resistance to interlayer shear, excellent high temperature resistance and ablation resistance, it is an advanced composite material used in highend equipment such as launch vehicles, missiles, and aircraft. Yong Liu (8) studied the mechanical properties and microstructure of $2.5 \mathrm{D}$ quartz fiber reinforced silica composites, and concluded that the shear stressdisplacement curve of composites changes nonlinearly and the composites show good toughness in the radial direction. Qing Wang (9) studied the effect of $\mathrm{ZrO}_{2}$ coating from the mechanical properties of $2.5 \mathrm{D} \mathrm{SiC}$ fiber reinforced $\mathrm{SiO}_{2}$ composites, the results show that the flexural strength of $\mathrm{ZrO}_{2}$ coated $\mathrm{SiC}$ fiber reinforced $\mathrm{SiO}_{2}$ composites is about twice that of uncoated composites, the strength of the composite tested at $1200^{\circ} \mathrm{C}$ increased by about $12 \%$ compared to the strength of the sample tested at room temperature.

The curing degree of the resin has a very large effect on the properties of the composite (10-13). In general, the greater the degree of cure of the resin, the better the properties of the composite (14-16). However, in the actual production of composite materials, due to raw materials, curing processes, molds and other factors, the curing degree of composite materials often does not reach a higher level, or if the curing degree is to reach a certain higher value, it will cost more time and energy. In this paper, the boron phenolic resin was used as the matrix 
and 2.5D quartz fiber was used as the reinforcing material to prepare $2.5 \mathrm{D}$ quartz fiber reinforced boron phenolic composite and studying the effect of curing degree on its mechanical properties and thermal properties.

\section{Experimental details}

\subsection{Experimental materials}

Thermoset phenolic resin was purchased from Shanxi Taihang Fire Resistant Polymer Company (China) and more details on the resin are shown in Table 1. 2.5D quartz fiber braid, $C$ type, (the single layer thickness is $2 \mathrm{~mm}$ and the woven structure is shallow cross-linking; the fiber volume content is $38 \%$ ) produced by Hubei Jingzhou Feilihua Quartz Glass Company (China). Acetone(AR) was supplied by Sinopharm Reagent Company (China). Absolute ethanol(AR) was supplied by Sinopharm Reagent Company (China).

\subsection{Preparation of composite materials}

First, the 2.5D quartz fiber was dried at $80^{\circ} \mathrm{C}$ for $5 \mathrm{~h}$ using a vacuum drying oven, and the powdered boron phenolic resin was dissolved using absolute ethanol. The 2.5D quartz fiber was cut to a suitable size, and the mass

Table 1: Compositions of boron phenolic resin.

\begin{tabular}{lrrrrr}
\hline Component & resin phenol & $\begin{array}{r}\text { phenol } \\
\text { derivative }\end{array}$ & $\begin{array}{r}\text { free } \\
\text { aldehyde }\end{array}$ & \\
\hline Mass fraction (wt\%) & 92.29 & 4.21 & 2.07 & 0.87 & 0.56 \\
\hline
\end{tabular}

ratio of the boron phenolic resin to the 2.5D quartz fiber was calculated based on the fiber mass, the fiber volume content, and weighing dissolved boron phenolic resin. Next, the weighed boron phenolic resin was uniformly impregnated with 2.5D quartz fiber by a wet hand lay-up process, and then the solvent was removed in a vacuum drying oven to obtain a 2.5D quartz fiber-boron phenolic resin prepreg. Cut the prepreg to fit the size of the mold and cure it under different curing parameters to obtain a 2.5D quartz fiber-boron phenolic resin composite material with different degrees of cure. Numbering composite samples, from CM-A1 to CM-C4, as shown in Table 2. Figure 1 is a picture of the cured 2.5D quartz fiber reinforced boron phenolic resin composite sample.

\subsection{Material testing and performance characterization}

The curing degree of the composite material was measured by solvent the extraction method. The part

Table 2: Curing parameters of composite samples.

\begin{tabular}{lrr}
\hline Samples & Curing temperature $\left({ }^{\circ} \mathrm{C}\right)$ & Holding time $(\mathrm{min})$ \\
\hline CM-A1 & 130 & 30 \\
CM-A2 & & 60 \\
CM-A3 & & 120 \\
CM-A4 & & 180 \\
CM-B1 & 150 & 30 \\
CM-B2 & & 60 \\
CM-B3 & & 120 \\
CM-B4 & & 180 \\
CM-C1 & & 30 \\
CM-C2 & 180 & 60 \\
CM-C3 & & 120 \\
CM-C4 & & 180 \\
\hline
\end{tabular}

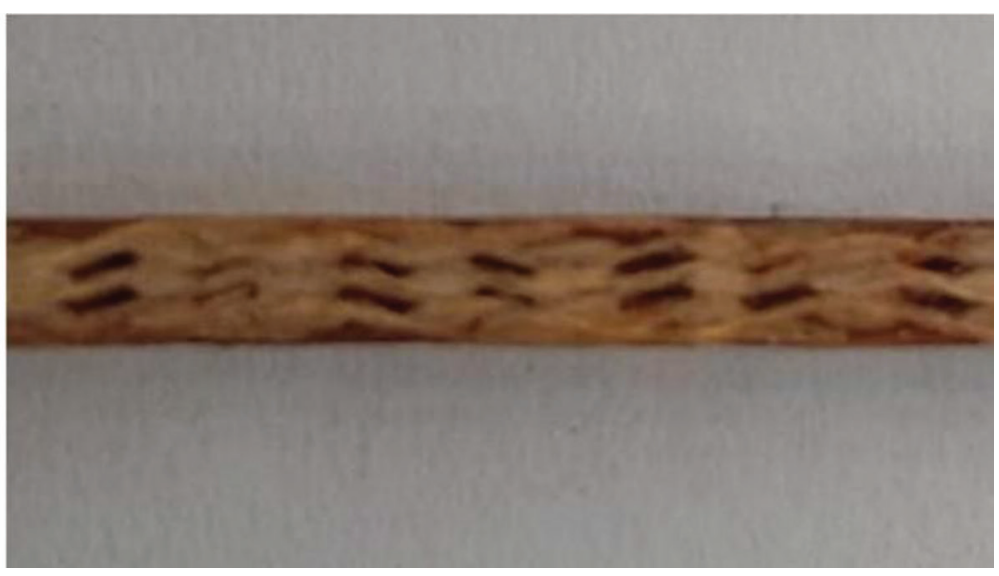

Figure 1: Pictures of the cured 2.5D quartz fiber reinforced boron phenolic resin composite sample. 
Sample stereogram

$1.5 \mathrm{~mm}$

$3 \mathrm{~mm}$

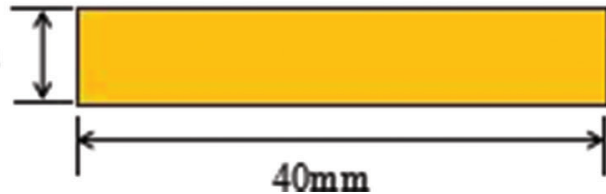

Main view

Top view

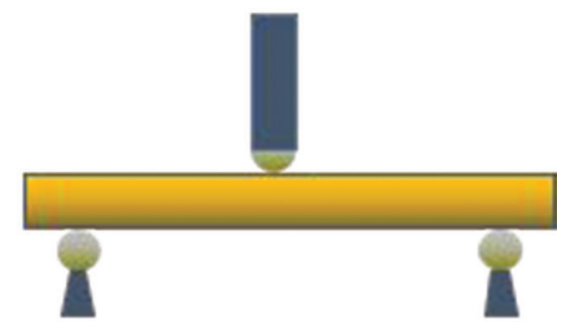

Figure 2: The size of the curved sample and schematic diagram of the flexural test.

of the composite material close to the measured resin content was selected. The sample was processed into a powder sample by a trowel, and the powder sample was sieved through a $0.4 \mathrm{~mm}$ standard sieve to obtain a powder sample to be determined. Then, the powder samples are extracted from acetone, and the extracted sample was subjected to suction filtration and drying treatment. The finally the curing degree of the composite material was calculated by weighing. The flexural strength of the composites with different degrees of cure was tested for a mechanical testing machine using a "three-point bending method" with a loading rate of $2 \mathrm{~mm} / \mathrm{min}$, the sample size and test schematic shown in Figure 2. The cross section of the composite was observed using scanning electron microscopy (JSM-IT300 model of Japan Electronics Co., Ltd., sample size is less than $20 \mathrm{~mm} \times 20 \mathrm{~mm}$, Pt treatment on the surface of the sample, Secondary electron imaging and the exposure time is $20 \mathrm{~s}$, the vacuum degree reaches $10^{-6} \mathrm{~Pa}$ ), and the bending failure mechanism of the composite was analyzed. The thermal performance of the composite material was tested by a high temperature TG-DSC thermal analyzer from NETZSCH, Germany. The heating rate was $10.0^{\circ} \mathrm{C} / \mathrm{min}$, and the temperature range was $25^{\circ} \mathrm{C}$ to $1000^{\circ} \mathrm{C}$ in a nitrogen atmosphere.

\section{Results and discussion}

\subsection{Curing degree and flexural strength of 2.5D quartz fiber-boron phenolic resin composite}

The Figure 3 shows the change in the curing degree of the sample under different curing processes, and the Figure 4 shows the bending strength of the sample at different degrees of cure. As shown in Figure 3, the Ct

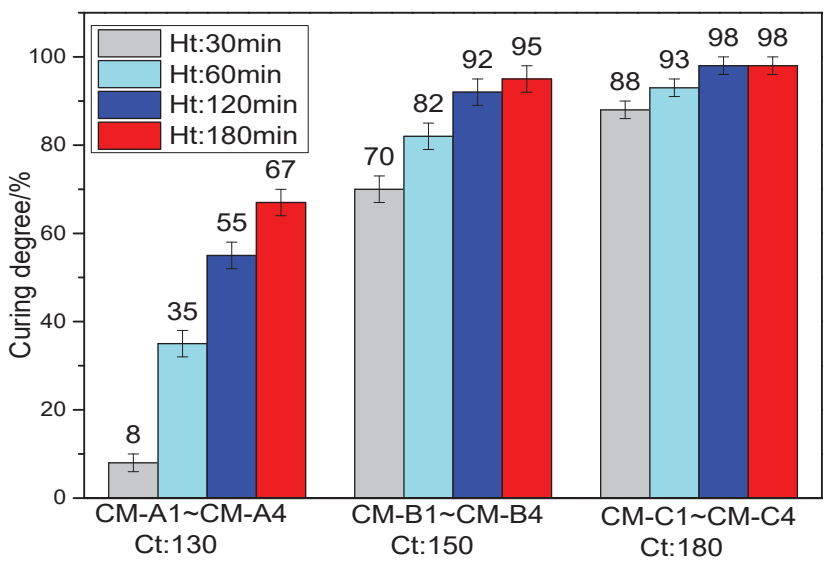

Figure 3: Curing degree of different curing processes ( $\mathrm{Ht}$ - Holding time, $\mathrm{Ct}$ - curing temperature).

(curing temperature) and the Ht (holding time) have an effect on the curing degree, The curing degree of sample increases with the increase of $\mathrm{Ct}$ or $\mathrm{Ht}$, but the degree of influence is different. When the $\mathrm{Ht}$ is the same, it is clear that the higher the $\mathrm{Ct}$, the higher the curing degree of the sample, The overall curing degree of Samples CM-A1 CM-A4 is significantly lower than that of Samples CM-C1 CM-C4, the curing degree of CM-A4 is 67\%, which is $46 \%$ lower than the CM-C4 with $98 \%$ curing degree, the sample $\mathrm{CM}-\mathrm{C} 1$ with a curing temperature of $180^{\circ} \mathrm{C}$ can achieve $88 \%$ cure even in the shortest holding time. Therefore, the Ct contributes more to the curing degree, but from another point of view, the ideal curing degree can be achieved by extending the holding time at a lower temperature. As can be seen from Figure 4, the bending strength of the sample increases as the degree of cure increases, but this trend is not linear. The curing degree of the composite material increased in $70 \%$ to $92 \%$, the flexural strength reached $310.56 \mathrm{MPa}$ from $185.34 \mathrm{MPa}$, the flexural strength improvement rate of the material is $67 \%$, and the curing degree was from $85 \%$ to $95 \%$, and the flexural strength was from $271.08 \mathrm{MPa}$ to $320.32 \mathrm{MPa}$, 
the rate is $18 \%$. When the curing degree of the composite material reaches $90 \%$ or higher, the flexural strength of the composite material exceeds $300 \mathrm{MPa}$, and the flexural strength differs little in this range (17). Therefore, when the curing degree reaches a certain value, the flexural strength of the sample does not rise significantly as the curing degree increases.

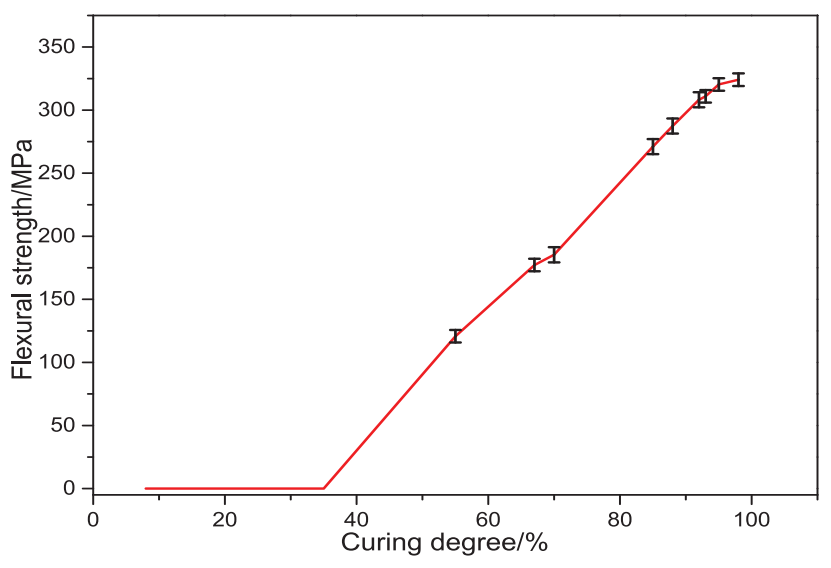

Figure 4: Flexural strength of different curing degree.

\subsection{Analysis of sectional micromorpho- logy and flexural failure mechanism of composites}

In order to analyze the effect of curing degree on the micro-morphology of bending failure of 2.5D quartz fiber reinforced boron phenolic resin composites and the flexural failure mechanism of composites, scanning electron microscopy analysis was performed on the curved section of CM-B1 with curing degree of $70 \%$ and CM-C3 with curing degree of $98 \%$, the resulting SEM images are shown in Figures 5 and 6. It can be seen from the SEM image that the fiber surface on the curved section of the sample CM-B1 is relatively smooth, almost no resin matrix is attached, and the resin and fiber de-bounding, as shown in Figure $5 b$.

In contrast, the surface of the fiber on the cross section of the sample CM-C3 was rough, as shown in Figure 6, and the resin was attached to the surface of the fiber, and the fiber and the resin did not separate. It can be seen from Figure $5 \mathrm{~d}$ that the resin between the fibers has cracks of different sizes and even cracks, but in Figure 6d, the resin

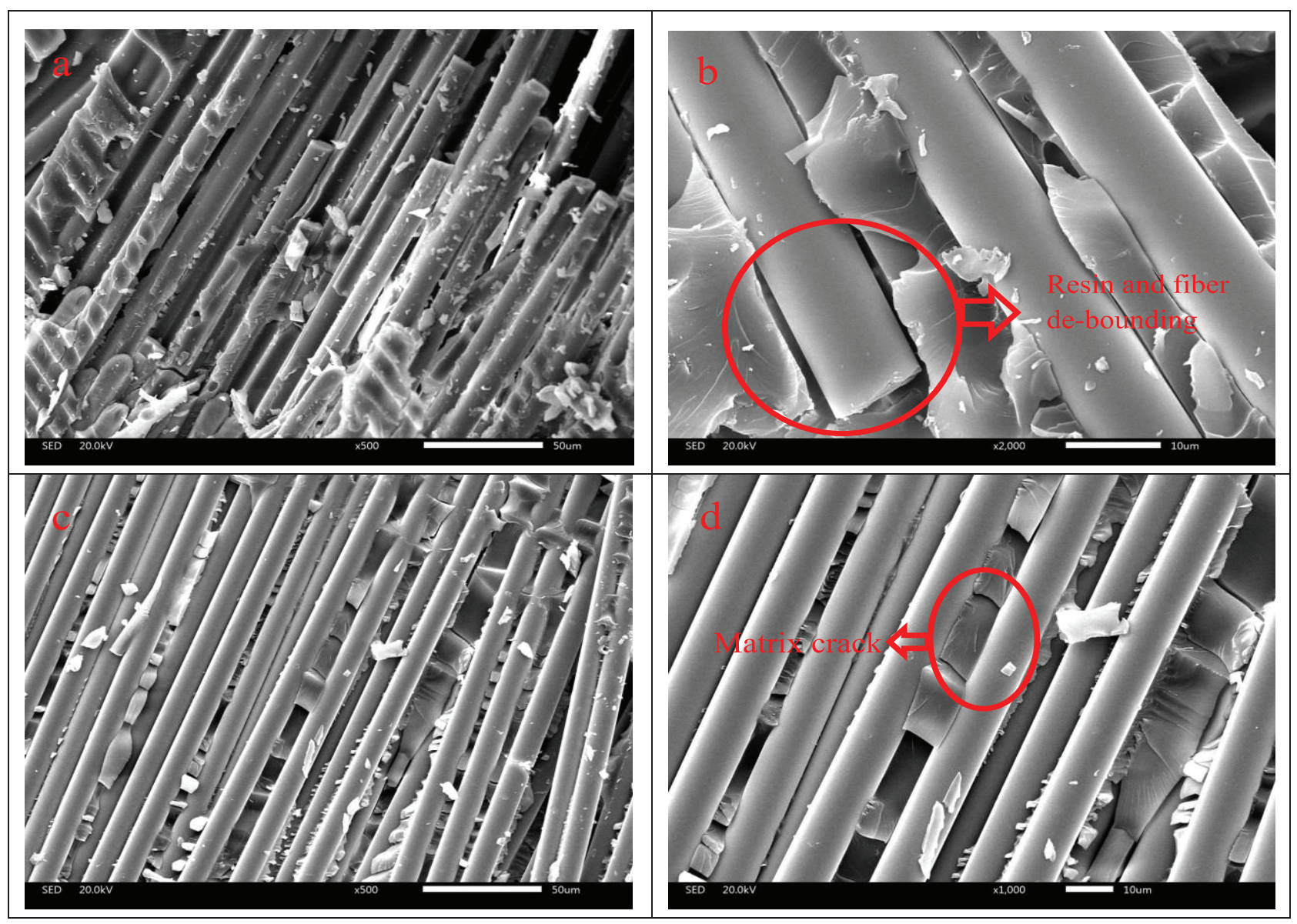

Figure 5: SEM image of CM-B1 bending failure. 
matrix is well attached to the surface of the fibers and the interface remains intact. This shows that the degree of cure will affect the interface properties of the composite. The reason for these occurrences is that when the resin is not cured enough, the resin strength is low, cracks or even cracks are easily caused by bending and compression, and the interface strength between the resin and the fiber is low, thereby affecting the bending strength of the composite. When the degree of curing of the resin is high, the degree of cross-linking of the resin is high, the resin strength is high, and the interface property between the resin and the fiber is good. When the composite material is subjected to bending and compression, the resin can effectively transmit load and distribute load. It can also be seen from the two SEM images that, regardless of the degree of curing, most of the fibers are intact after the sample is subjected to bending failure, and few fibers are single or single-strand broken, which shows that the 2.5D structure have excellent Integrity.

Therefore, it can be inferred that the macroscopic change of the 2.5D fiber reinforced composite material under bending to load may beas shown in Figure7. Figure 4a shows the state of the fiber when the composite material are not subjected to load, and Figure $4 \mathrm{~b}$ is the state of the fiber when the composite is under load. Since the warp yarn is not in a fully stretched state in the structure of the 2.5D fiber, but is bent through several layers of weft yarns, the tension is less. Therefore, when the composite material are subjected to a load, it can be deformed by the fibers, so that the load applied to the surface perpendicular to the composite material is distributed over the warp yarns of the respective layers, and the warp yarns are deformed to resist the load. From the above analysis, it can be inferred that the composite material may have several failure mechanisms $(18,19)$ as shown in Figure 8. When the 2.5D quartz fiber reinforced boron phenolic resin composite material is subjected to a bending load, if the curing degree of the composite material is not high, it is likely that the resin matrix is cracked or even broken, as shown in Figures 8a and 8b. As the load continues to increase, the deformation of the composite increases. Due to the poor interfacial properties of the resin matrix and the fiber, the deformation between the fiber and the resin under bending to load is inconsistent, and the resin

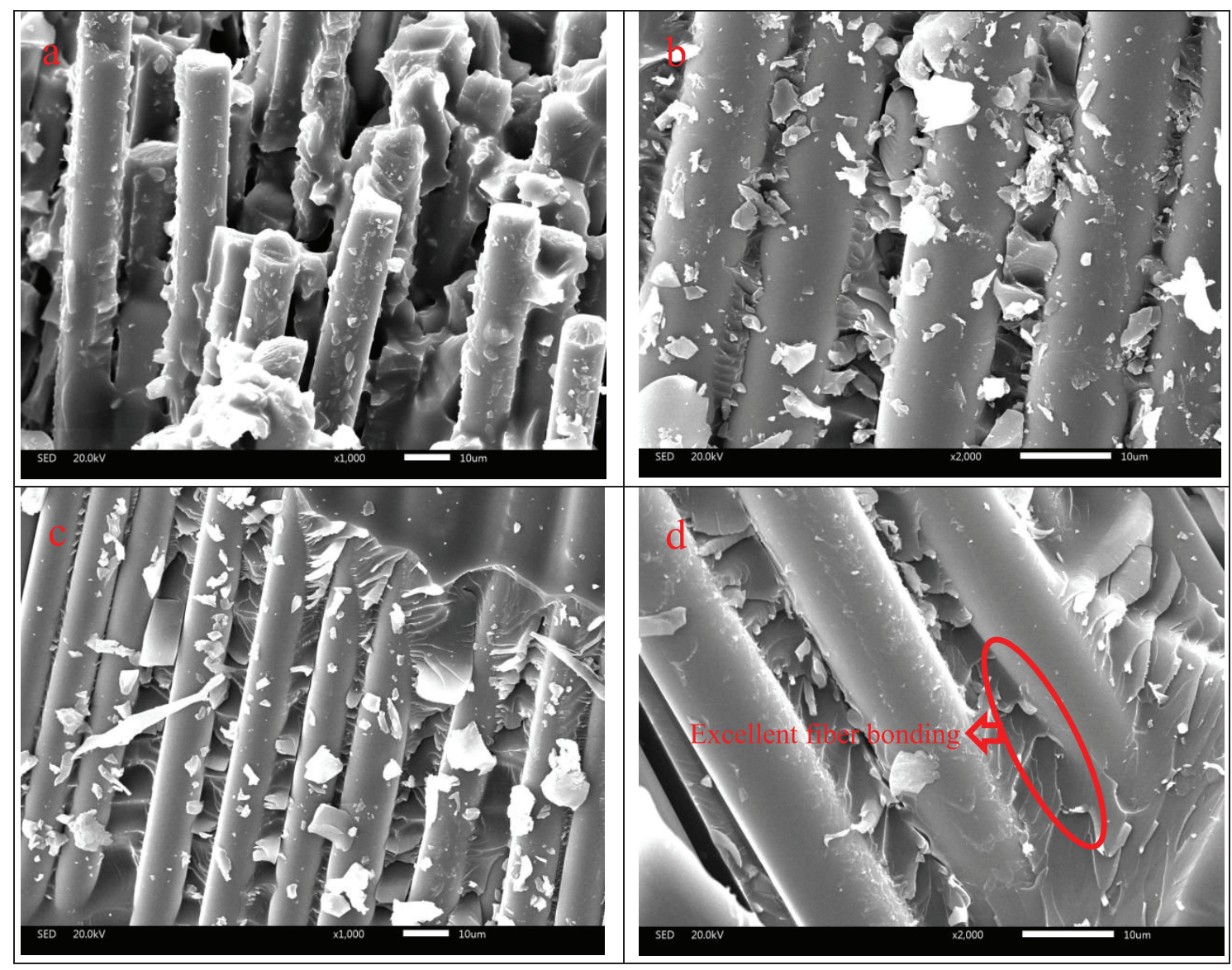

Figure 6: $\mathrm{SEM}$ image of $\mathrm{CM}-\mathrm{C} 3$ bending failure. 
may gradually peel off from the fiber, as shown in Figure 8c. The damaged resin remains between the fibers, but the protective fiber has been lost, and the fiber is easily broken, as shown in Figure 8d. When the composite has a high curing degree, the composite tends to be brittle when subjected to a bending load, that is, it is more likely that the fiber breaks together with the matrix.

\subsection{Thermal properties of composite materials}

The TG curves and the DTG curves of the composite samples CM-B1, CM-B2, CM-B3 and CM-C4 are shown in Figures 9 and 10, the thermal decomposition parameters of the composite can be obtained from the TG data, as shown in the Table 3. In order to eliminate the error caused by the difference in fiber content of each sample, the figures and the table data do not contain the weight of the fiber. It can be seen from Figure 9 that the thermal weight loss of the composite sample mainly occurs to the range of $300^{\circ} \mathrm{C} \sim 700^{\circ} \mathrm{C}$, at this stage the composite resin matrix cracking reaction, the weight is rapidly reduced. However, the weight loss of composite materials with different curing degree is different. It can be seen from the data onto Table 3 that the temperature $\mathrm{T}_{10 \%}$ of $10 \%$ weight loss moves toward high temperature as the curing degree increases, the CM-B1 loses $10 \%$ of its temperature at $283.3^{\circ} \mathrm{C}$, while the CM-C4 loses $10 \%$ of its temperature at $461.2^{\circ} \mathrm{C}$, the curing degree differs by less than $30 \%$, while $\mathrm{T}_{10 \%}$ differs by $180^{\circ} \mathrm{C}$. The reason is that the composite resin matrix with low curing degree contains a large amount of resin which does not undergo cross-linking reaction. During heating, these
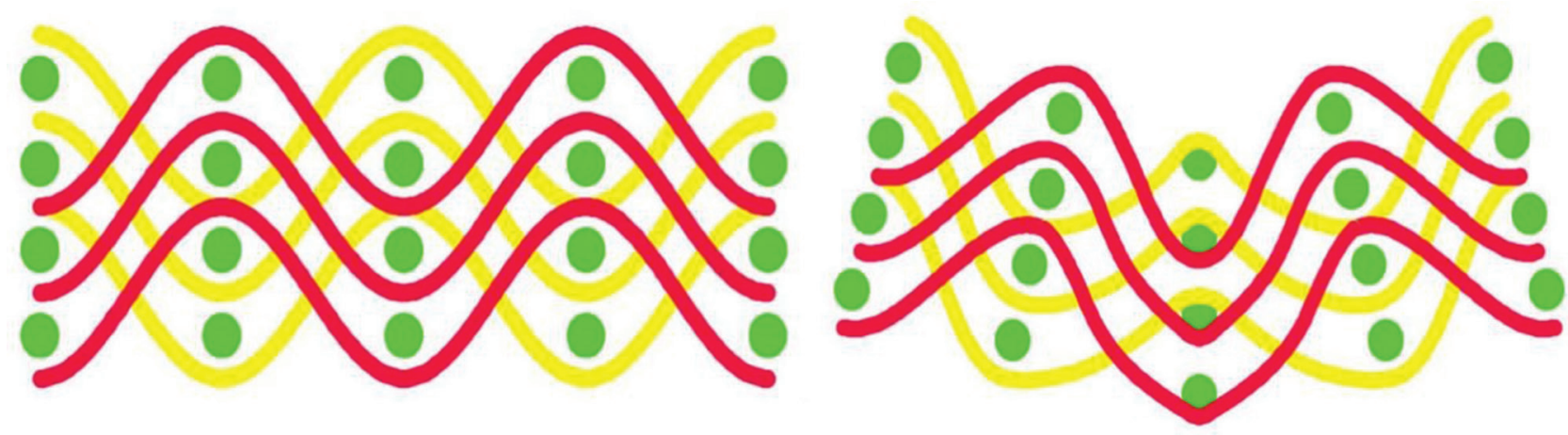

Figure 7: Form of 2.5D structural fiber: (a) composite material is not loaded; (b) composite material subjected to bending load.

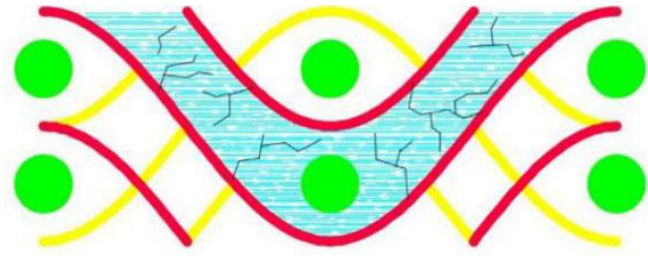

(a)

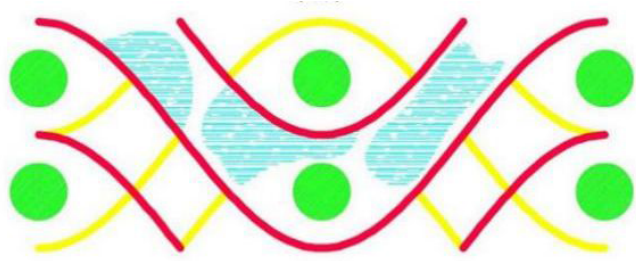

(c)

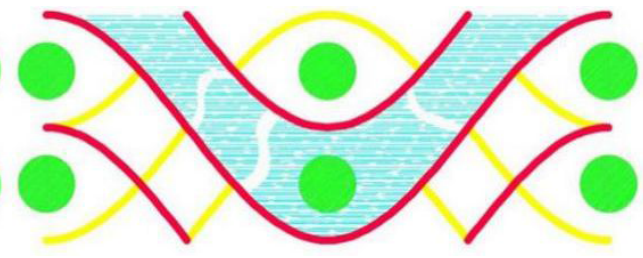

(b)

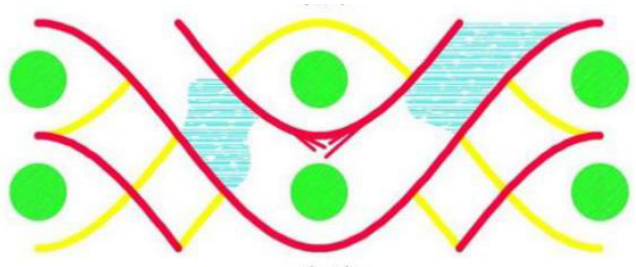

(d)

Figure 8: Fiber and resin state when composite material is subjected to bending load: (a) crack in the resin matrix; (b) resin matrix fracture; (c) resin and fiber stripping; (d) fiber and resin break. 
resins begin to undergo cross-linking reaction, and the reaction produces volatile small molecules, which reduces the weight. In addition, when the temperature reaches the decomposition temperature of the resin, the two reactions work together to make the $\mathrm{T}_{10 \%}$ of the composite material lower. As the degree of cure increases, the former reaction becomes weaker and weaker, so that $\mathrm{T}_{10 \%}$ moves to a high temperature as the curing degree increases. The residual weight of the composite at $1000^{\circ} \mathrm{C}$ is similar to $\mathrm{T}_{10 \%}$, the difference is that the residual weight of each composite sample is not much different at $1000^{\circ} \mathrm{C}$, and $70 \%$ curing degree and $98 \%$ curing degree composite material only differs by $3 \%$ at $1000^{\circ} \mathrm{C}$ residual weight.

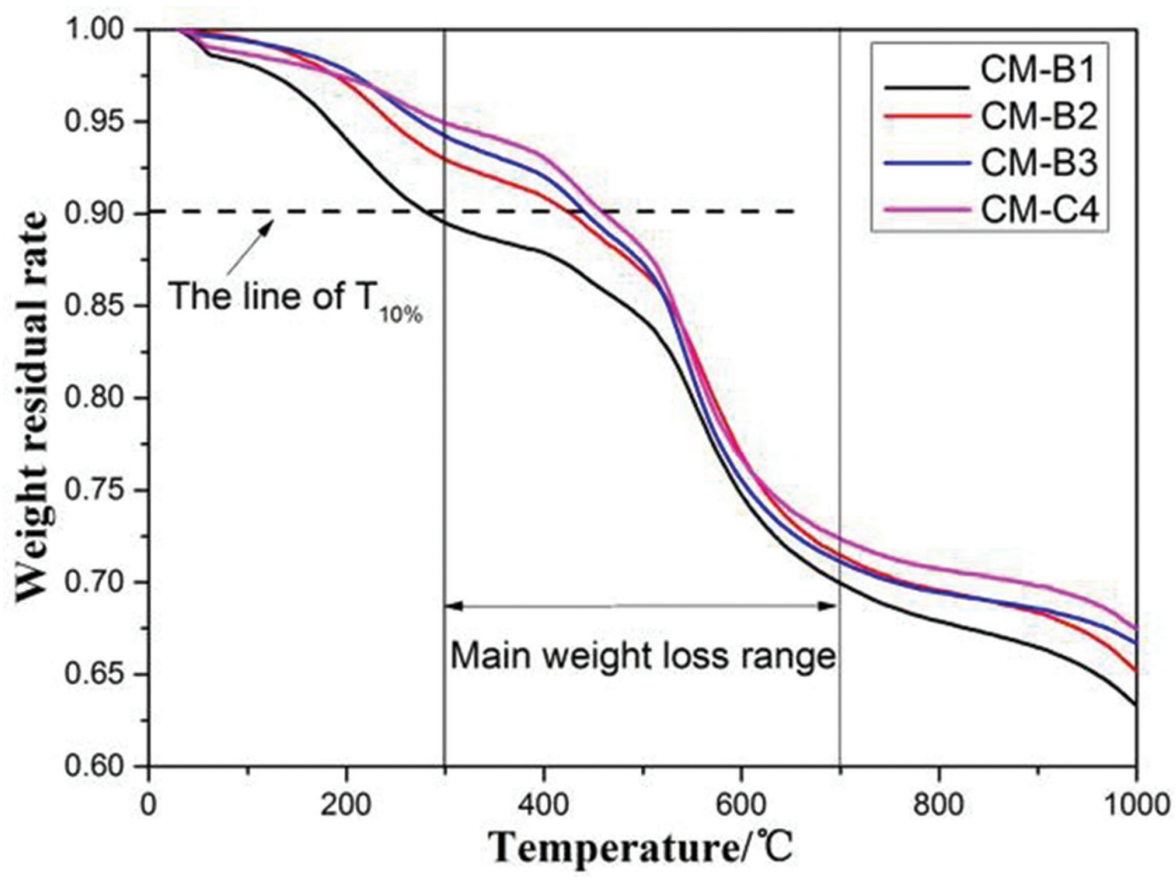

Figure 9: TG curve for composites.

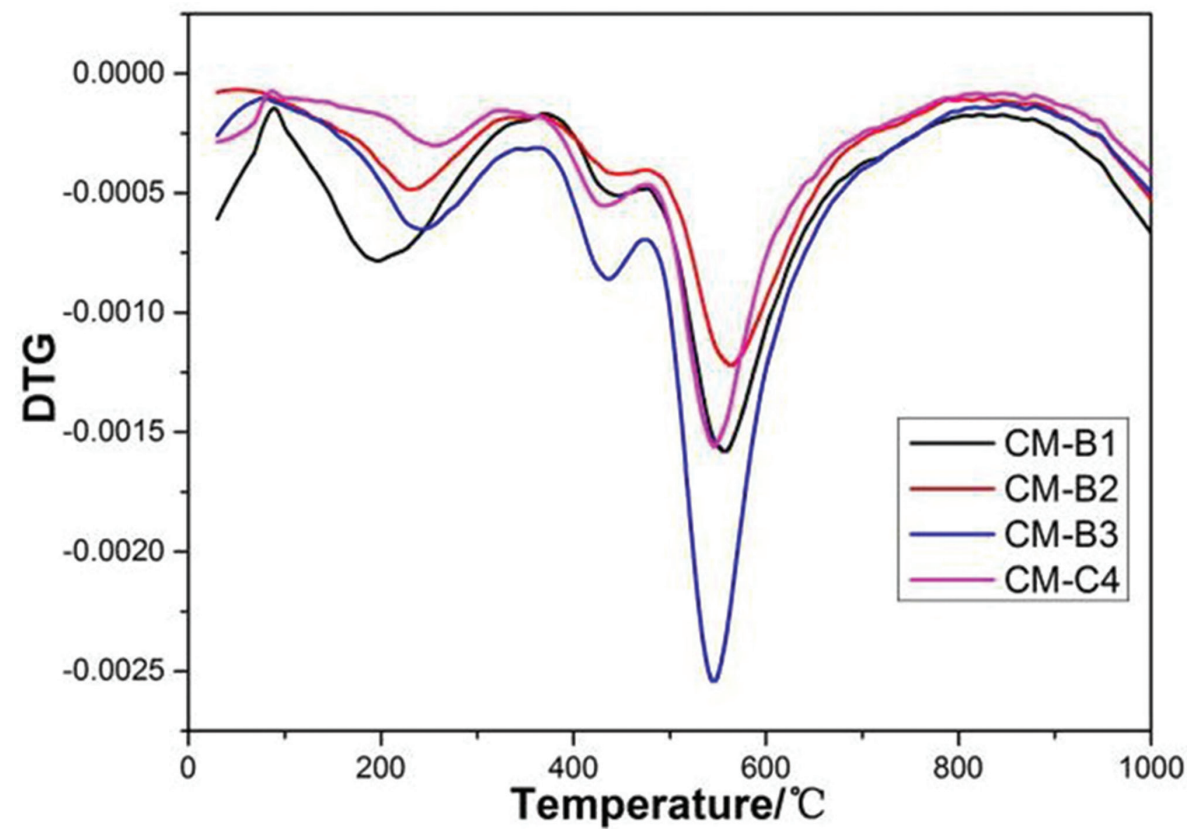

Figure 10: DTG curve for composites. 
Table 3: Thermal decomposition parameters of composites.

\begin{tabular}{lrrrr}
\hline Sample & $\begin{array}{r}\text { Curing } \\
\text { degree (\%) }\end{array}$ & $\mathrm{T10 \%}\left({ }^{\circ} \mathrm{C}\right)$ & $\begin{array}{r}\text { Maximum } \\
\text { degradation } \\
\text { temperature } \\
\left({ }^{\circ} \mathrm{C}\right)\end{array}$ & $\begin{array}{r}\text { Residue } \\
\text { weight } \\
(\%)\end{array}$ \\
\hline CM-B1 & 70 & 283.3 & 563.8 & 63.29 \\
CM-B2 & 85 & 427.3 & 555.3 & 65.14 \\
CM-B3 & 92 & 442.7 & 545.5 & 66.67 \\
CM-C4 & 98 & 461.2 & 553.4 & 67.44 \\
\hline
\end{tabular}

\section{Conclusions}

(1) Curing temperature and holding time have a great influence on the curing degree of $2.5 \mathrm{D}$ quartz fiber reinforced boron phenolic resin composite. The higher the curing temperature, the faster the curing degree of the composite increases; however the curing degree can be achieved by extending the holding time at a lower curing temperature. The improvement of the curing degree is beneficial to the bending property of the composite. When the curing degree is higher than $90 \%$, the rate of change of the bending strength is small, and the bending strength is higher than $300 \mathrm{MPa}$.

(2) The SEM results show that the increase of curing degree can improve the interface properties of $2.5 \mathrm{D}$ quartz fiber reinforced boron phenolic resin composites. When the composite material with a low curing degree is subjected to a bending load, the matrix is cracked or broken, then the resin matrix is peeled off from the fibers, and finally the fibers are broken.

(3) The TG test showed that the degree of cure had a great influence on the pre-weightless temperature $\mathrm{T}_{10 \%}$ of the 2.5D quartz fiber reinforced boron phenolic resin composite. The higher the curing degree is, the better the increase of $\mathrm{T}_{10 \%}$; however when the degree of cure is higher than $90 \%$, the increase of $\mathrm{T}_{10 \%}$ is not obvious. The degree of curing has little effect on the residual weight of the material at $1000^{\circ} \mathrm{C}$. The residual weight of $70 \%$ curing degree and $98 \%$ curing degree differs only by $3 \%$ at $1000^{\circ} \mathrm{C}$.

\section{References}

1. Deng X., Chawla N., Three-dimensional (3D) modeling of the thermoelastic behavior of woven glass fiber-reinforced resin matrix composites. J. Mater. Sci., 2008, 43(19), 6468-6472.
2. Xue-Wei X.U., Jiao Y.N., Ying S., Impact properties of multidimensional multi-directional textile composites. J. Tianjin Polytechnic Univ., 2014, 33(1), 1-4.

3. Hu X., Sun Z., Yang F., Fatigue Hysteresis Behavior of 2.5D Woven C/SiC Composites: Theory and Experiments. Appl. Compos. Mater., 2017, 24(6), 1-17.

4. Jiao Y.N., Qiu P.X., Gao-Ning J.I., Mechanical properties of 2.5D woven composites with different volume rates in warp and weft directions. J. Tianjin Polytechnic Univ., 2015.

5. Gooch J.W., Quartz Fiber. Springer, New York, 2011.

6. Zhang Y., Cao J., Wang D., Synthesis of Boron Modified Phenolic Resin. Chin. J. Syn. Chem., 2004.

7. Yan L.S., Yao D.M., Yang X.J., Study on Boron-Phenolic Resin Ablative Materials. J. Solid Rocket Technol., 2000.

8. Liu Y., Zhu J., Chen Z., Mechanical properties and microstructure of 2.5D (shallow straight-joint) quartz fibers-reinforced silica composites by silicasol-infiltration-sintering. Ceram. Int., 2012, 38(1), 795-800.

9. Wang Q., Cao F., Xiang Y., Effects of $\mathrm{ZrO}_{2}$, coating on the strength improvement of 2.5D SiC $\mathrm{f} / \mathrm{SiO}_{2}$, composites. Ceram. Int., 2017, 43(1), 884-889.

10. Wachsman E.D., Frank C.W., Effect of cure history on the morphology of polyimide: Fluorescence spectroscopy as a method for determining the degree of cure. Polymer, 1988, 29(7), 1191-1197.

11. Uddin M.A., Alam M.O., Chan Y.C., Adhesion strength and contact resistance of flip chip on flex packages-effect of curing degree of anisotropic conductive film. Microelectron. Reliab., 2004, 44(3), 505-514.

12. Montserrat S., Flaqué C., Pagès P., Effect of the crosslinking degree on curing kinetics of an epoxy-anhydride system. J. Appl. Polym. Sci., 2010, 56(11), 1413-1421.

13. Labronici M., Ishida H., Effect of degree of cure and fiber content on the mechanical and dynamic mechanical properties of carbon fiber reinforced PMR-15 polyimide composites. Polym. Composite., 2010, 20(4), 515-523.

14. Maas T.A.M.M., Optimalization of processing conditions for thermosetting polymers by determination of the degree of curing with a differential scanning calorimeter. Polym. Eng. Sci., 2010, 18(1), 29-32.

15. Heba F., Mouzali M., Abadie M.J.M., Effect of the crosslinking degree on curing kinetics of an epoxy-acid copolymer system. J. Appl. Polym. Sci., 2010, 90(10), 2834-2839.

16. So S., Rudin A., Effects of resin and curing parameters on the degree of cure of resole phenolic resins and woodflour composites. J. Appl. Polym. Sci., 2010, 40(11-12), 2135-2149.

17. Li S.S., Chen L., Jiao Y.N., Experimental Research on Bending Behavior of 2.5D Woven Fabrics. Adv. Mater. Res., 2011, 152-153, 254-258.

18. Song J., Wen W., Cui H., Finite Element Analysis of 2.5D Woven Composites, Part II: Damage Behavior Simulation and Strength Prediction. Appl. Compos. Mater., 2015, 23(1), 1-25.

19. Zhong S., Guo L., Liu G., A continuum damage model for three-dimensional woven composites and finite element implementation. Compos. Struct., 2015, 128, 1-9. 